\title{
ANALISIS KESESUAIAN FASILITAS PARKIR ON-STREET DENGAN MEMANFAATKAN SISTEM INFORMASI GEOGRAFI DAN CITRA QUICKBIRD DI KECAMATAN MEDAN MAIMUN
}

\author{
Rizky Harrianto Nainggolan1, Muhammad Ridha Syafii Damanik²
}

\author{
${ }^{1}$ Alumnus Jurusan Pendidikan Geografi Fakultas Ilmu Sosial Universitas Negeri Medan \\ Email : rizkynainggolan6@gmail.com \\ 2Dosen Jurusan Pendidikan Geografi Fakultas Ilmu Sosial Universitas Negeri Medan \\ Jl. Willem Iskandar Psr V Medan Estate Medan 20211 \\ Telp.(061) 6627549. \\ Email: mridhadamanik@unimed.ac.id
}

\begin{abstract}
ABSTRAK
Tujuan penelitian ini adalah untuk mengetahui persebaran dan kesesuaian fasilitas OnStreet Parking di Kecamatan Medan Maimun serta mengukur tingkat akurasi citra Quickbird sebagai alat analisis penetapan fasilitas On - Sreet Paking. Populasi dalam penelitian ini adalah seluruh unit jalan di Kecamatan Medan Mauium Kota Medan, sedangkan sampel penelitian adalah jaringan jalan yang ditetapkan oleh Dinas Perhubungan Kota Medan sebagai fasilitas parkir on-street. Teknik pengumpulan data yang digunakan adalah studi dokumenter, interpretasi citra, dan observasi. Sebaran fasilitas parkir digambarkan dengan menggunakan sistem informasi geografis, sedangkan pengukuran tingkat kesesuaian fasilitias parkir mengacu pada Keputusan Menteri Perhubungan No:66 tahun 1993 Tentang Fasilitas Parkir untuk Umum dan Keputusan Direktorat Jenderal Perhubungan Darat Nomor 272/HK.105/DRJD/1996 Tentang Pedoman Teknis Penyelenggaraan Fasilitas Parkir. Teknik sampling dalam penghitungan tingkat akurasi interpretasi citra yaitu dengan purposive sampling menggunakan 10 titik lokasi parkir. Analisis data dilakukan secara deskriptif kualitatif. Hasil dari penelitian menunjukkan bahwa sebaran fasilitas parkir on-street di Kecamatan Medan Maimun tidak merata dan terkonsentrasi di Kelurahan Aur yang merupakan lokasi paling sibuk di Kecamatan Medan Maimun. Prosentase fasilitas parkir on-street di Kecamatan Medan Maimun yang sesuai adalah $54.49 \%$ sedangkan $45.51 \%$ dikategorikan tidak sesuai. Aturan larangan parkir $25 \mathrm{~m}$ sebelum dan sesudah persimpangan adalah yang paling sering tidak diikuti dalam penetapan fasilitas parkir on-street di Kecamatan Medan Maimun. Terdapat 46.74\% dari total jaringan jalan Kecamatan Medan Maimun dapat direkomendasikan sebagai fasilitas parkir on-street sesuai dengan peraturan Direktorat Jenderal Perhubungan Darat. Tingkat akurasi interpretasi jaringan jalan menggunakan Citra Quickbird di Kecamatan Medan Maimun sebesar 98.03\%.
\end{abstract}

\section{Kata Kunci: Fasilitas Parkir on-street, Kesesuaian, Interpretasi, Akurasi}

\section{PENDAHULUAN}

Kemampuan mobilisasi kota berpengaruh penting dalam pencapaian efisiensi kegiatan ekonomi. Sarana dan prasarana seperti jalan dan kendaraan merupakan alat mobilitas penduduk. Seiring dengan pertumbuhan jumlah kendaraan yang saat ini cukup pesat, berdasarkan data Direktorat Lalu Lintas Kepolisian Daerah Sumatera Utara sampai dengan tahun 2014, jumlah kendaraan yang ada di Kota Medan 5.531.777. Dari jumlah tersebut, sepeda motor mendominasi sebanyak $86,29 \%$, mobil penumpangan 7,91 persen, mobil barang $4,50 \%$ dan bus $1,30 \%$ 
(www.lamanmedan.com) tidak sebanding dengan pembangunan jalan yang relatif konstan dikarenakan nilai komersil tanah yang tinggi. Kendaraan yang digunakan ada saatnya akan berhenti untuk beberapa waktu hingga dikemudikan lagi. Perhentian yang dimaksud adalah parkir, sebahagian besar fasilitas parkir yang memanfaatkan badanjalan sehingga peran jalan berfungsi ganda dan badan jalan akan menyempit dan dapat menimbulkan kemacetan dan lakalantas.

Sejalan dengan perkembangan teknologi khususnya dalam bidang pemetaan, pemanfaatan penginderaan jauh dan Sistem Informasi Geografi dapat digunakan untuk mempermudah melakukan analisis kesesuaian fasilitas parkir yang telah ditetapkan oleh Dinas Perhubungan Kota Medan di Kecamatan Medan Maimun. Hal ini didasari dari aspek efisiensi dan efektifitas penelitian, pengukuran data acuan dengan melakukan interpretasi citra dan analisis spasial dengan menggunakan peta. Penggunaan citra beresolusi tinggi sangat memudahkan visualisasi kriteria fasilitas parkir yang ada di Kecamatan Medan Maimun. Citra Quickbird Kecamatan Medan Maimun dijadikan sebagai acuan utama dalam penelitian ini sebagai analisis kompleks ruang perkotaan seperti luas badan jalan dan jarak persimpangan jalan bebas hambatan dengan mengkaitkannya terhadap ketersediaan fasilitas parkir umum khususnya jenis On-Street Parking.

Penelitian ini bertujuan untuk memetakan sebaran parkir on-street di Kecamatan Medan Maimun yang ditetapkan oleh Dinas Perhubungan Kota Medan dan menganalisis kesesuaian penetapan fasilitas parkir tersebut berdasarkan Keputusan Menteri Perhubungan No:66 tahun 1993 Tentang Fasilitas Parkir untuk Umum dan Keputusan Direktorat Jenderal Perhubungan Darat Nomor 272/HK.105/DRJD/1996 Tentang Pedoman Teknis Penyelenggaraan Fasilitas Parkir. Penelitian ini juga bertujuan untuk mengetahui tingkat aakurasi interpretasi citra Quickbird dalam menganalisis persebaran fasilitas On-Street Parking dengan hasil interpretasi citra.

\section{METODE PENELITIAN}

Populasi dalam penelitian ini adalah seluruh unit jaringan jalan yang tampak dan dapat dikenali pada Citra Quickbird wilayah Kecamtan Medan Maimun dan seluruh jalan dijadikan sebagai sampel, dan pada penghitungan tingkat akurasi interpretasi citra Quickbird digunakan teknik purposive sampling yaitu dengan menentukan 10 titik lokasi pengukuran yang dapat mewakili seluruh jaring jalan di Kecamatan Medan Maimun. Teknik pengumpulan data dilakukan dengan observasi, pengukuran lapangan yakni menyaring dan menganalisis data sekunder dari berbagai Instansi berupa data dalam bentuk tabel dan peta. Data yang diekstrak dari citra Quickbird adalah jaringan jalan, lebar jalan, panjang jalan, dan kelas jalan. Tingkat akurasi hasil interpretasi diuji dengan membandingkan hasil interpretasi dengan hasil observasi lapangan. Observasi lapangan juga bertujuan untuk pencatatan dan pengukuran lebar jalan di lapangan serta penentuan titik koordinat fasilitas parkir.

Analisis data dilakukan dengan mengoverlay peta sebaran fasilitas parkir di badan jalan yang disebar oleh Dinas Perhubungan Kota Medan dengan peraturan Keputusan Menteri Perhubungan No. 66 tahun 1993 Tentang Fasilitas Parkir untuk Umum dan Keputusan Dirjen Perhubungan Darat Nomor. 272/ HK.105/ DRJD/ 1996 Tentang Pedoman Teknis Penyelenggaraan Fasilitas Parkir. Bahan dan alat yang digunakan adalah citra quickbird cakupan Medan Maimun, peta administrasi, Peta Jaringan Jalan, Peta sebaran parkir, seperangkat komputer dengan software ArcGIS 10.1, Global Position System, dan Kamera Dijital. Sistme koordniat yang diginakan dalam pemetaan menggunakan sistem UTM (Universal Transverse Mercator) 
pada Zona 47 N. Penyajian analisis data menggunakan teknik deskriptif kualitatif dengan menyajikan data-data hasil observasi dan data sekunder berupa peta hasil jaringan jalan pemanfaatan fasilitas parkir badan jalan dari citra quickbird, dan narasi.

\section{HASIL PENELITIAN}

Hasil penelitian menunjukkan bahwa terdapat 17 jalan yang terindetifikasi ditetapkan sebagai fasilitas parkir on-street yang terbagi menjadi 36 titik parkir (Tabel.1)

Tabel 1. Sebaran Fasilitas Parkir on-street Berdasakan Nama Jalan

\begin{tabular}{|c|c|c|}
\hline No & Nama Jalan & Titik Parkir \\
\hline 1 & Katamso Dalam & 1 \\
\hline 2 & Ir. Juanda & 2 \\
\hline 3 & Suka Mulia & 2 \\
\hline 4 & Mesjid Raya & 1 \\
\hline 5 & Kol. Sugiono & 5 \\
\hline 6 & Warna & 1 \\
\hline 7 & Mangkubumi & 5 \\
\hline 8 & Brigjen Katamso & 6 \\
\hline 9 & Pemuda & 3 \\
\hline 10 & Suprapto & 1 \\
\hline 11 & Palang Merah & 3 \\
\hline 12 & Cakrawati & 1 \\
\hline 13 & Pegadaian & 1 \\
\hline 14 & Pemuda Baru I & 1 \\
\hline 15 & Pemuda Baru II & 1 \\
\hline 16 & Pemuda Baru III & 1 \\
\hline 17 & Zein Hamid & 1 \\
\hline & Jumlah & 36 \\
\hline
\end{tabular}

Sumber: Dinas Perhubungan Kota Medan, 2016

Ruas jalan yang paling banyak terdapat parkir on-street adalah Jalan Brigjen Katamso (6 titik), Jalan Kol. Sugiono (5 titik), dan Jalan Mangkubumi (5 titik), sedangkan jalan lainnya hanya terdapat 1 sampai 3 titik parkir.

Ditinjau dari wilayah administrasinya (Tabel. 2), kelurahan yang paling banyak terdapat titik parkir on-street adalah
Kelurahan Aur yaitu sebanyak 29 titik. Hal ini menunjukkan bahwa sebaran fasilitas parkir yang ditetapkan oleh Dinas Perhubungan Kota Medan memusat ke wilayah yang relatif sibuk yaitu kawasan pertokoan dan perkantoran. Sedangkan Kelurahan Hamdan merupakan satu satunya kelurahan yang tidak ditetapkan adanya fasilitas parkir on-street .

Tabel 2. Sebaran Fasilitas Parkir on-street Berdasarkan Kelurahan

\begin{tabular}{|c|c|c|}
\hline No & Kelurahan & Titik Parkir \\
\hline 1 & Aur & 29 \\
\hline 2 & Hamdan & 0 \\
\hline 3 & Jati & 1 \\
\hline 4 & Sukaraja & 2 \\
\hline 5 & Sei Mati & 2 \\
\hline 6 & KP. Baru & 2 \\
\hline & Jumlah & 36 \\
\hline
\end{tabular}

Sumber: Dinas Perhubungan Kota Medan, 2016 
Kecamatan Medan Maimun dilintasi jalan Arteri Sekunder dari Selatan hingga ke Utara Kecamatan Medan Maimun, dan merupakan jaringan jalan terpanjang di Kecamatan Medan Medan Maimun.
Fasilitas parkir on-street yang ditetapkan Dinas Perhubungan Kota Medan, titik fasilitas parkir berada di tipe Jalan Arteri Sekunder 25\% dan tipe Jalan Lokal Primer $30 \%$ (Tabel 3).

Tabel 3. Sebaran Fasilitas Parkir on-street Berdasarkan Kelurahan

\begin{tabular}{|c|c|c|}
\hline No & Tipe Jalan & Titik Parkir \\
\hline 1 & ArteriSekunder & 10 \\
\hline 2 & Kolektor Primer & 1 \\
\hline 3 & Kolektor Sekunder & 5 \\
\hline 4 & Lokal Primer & 11 \\
\hline 5 & LokalSekunder & 9 \\
\hline
\end{tabular}

Sumber: Dinas Perhubungan Kota Medan, 2016

Tipe parkir $45^{\circ}$ yang tersebar hanya di dua titik jalan yaitu dibagian Utara JL. Brigjen Katamso tepatnya di Kelurahan Aur persimpangan jalan Palan Merah dan jalan Palang Merah menuju rel kereta api, dan selebihnya Tipe parkir parkir sejajar atau $0^{\circ}$. Fasilitas parkir on-street 22 titik berada pada jalan dua lajur $66 \%$ parkir berada di jalan dua lajur. Secarakeseluruhan panajang jalan yang dimanfaatkan sebagagi fasilitas parkir Kecamatan Medan Maimun yaitu 9064 m atau $9 \mathrm{~km}$.

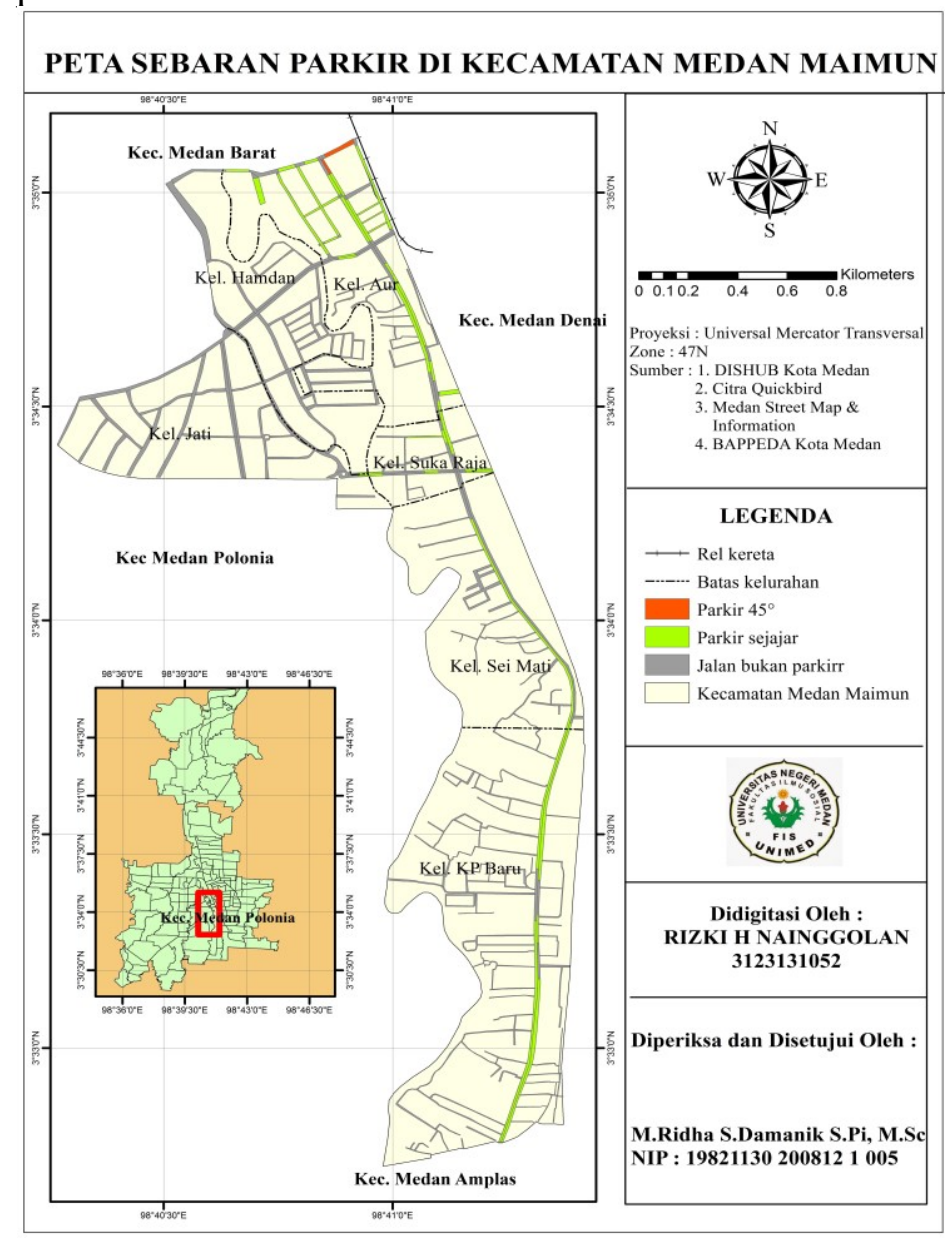

Gambar 1. Peta Sebaran Parkir Kecamatan Medan Maimum Kota Medan 
Prosentase kesesuaian fasilitas parkir on-street di Kecamatan Medan Maimun yaitu $54.49 \%$ dinyatakan sesuai dengan Direktorat Jenderal Perhubungan Darat, dan $45.51 \%$ tidak sesuai. Jalan Letjen Suprapto merupakan penetapan fasilitas parkir on-street yang paling sesuai yaitu 95.78\%. Sedangkan jalan yang paling tidak sesuai yaitu Jalan Palang Merah dan Jalan Cakrawati dengan tingkat kesesuaian masing-masing $35.50 \%$ dan $35.79 \%$.
Gambaran umum kesesuaian parkir di Kecamatan Medan Maimun yaitu jalan Pemuda Baru I yaitu $53.79 \%$ tingkat kesesuaian. Lahan fasilitas parkir yang ditetapkan Dinas Perhubungan Kota Medan yang paling besar adalah di Jalan Brigjen Katamso dan yang terkecil yaitu jalan Brigjen Katamso Dalam, jalan ini sebelah Selatan dari Istana Maimun dan merupakan jalan Buntu.

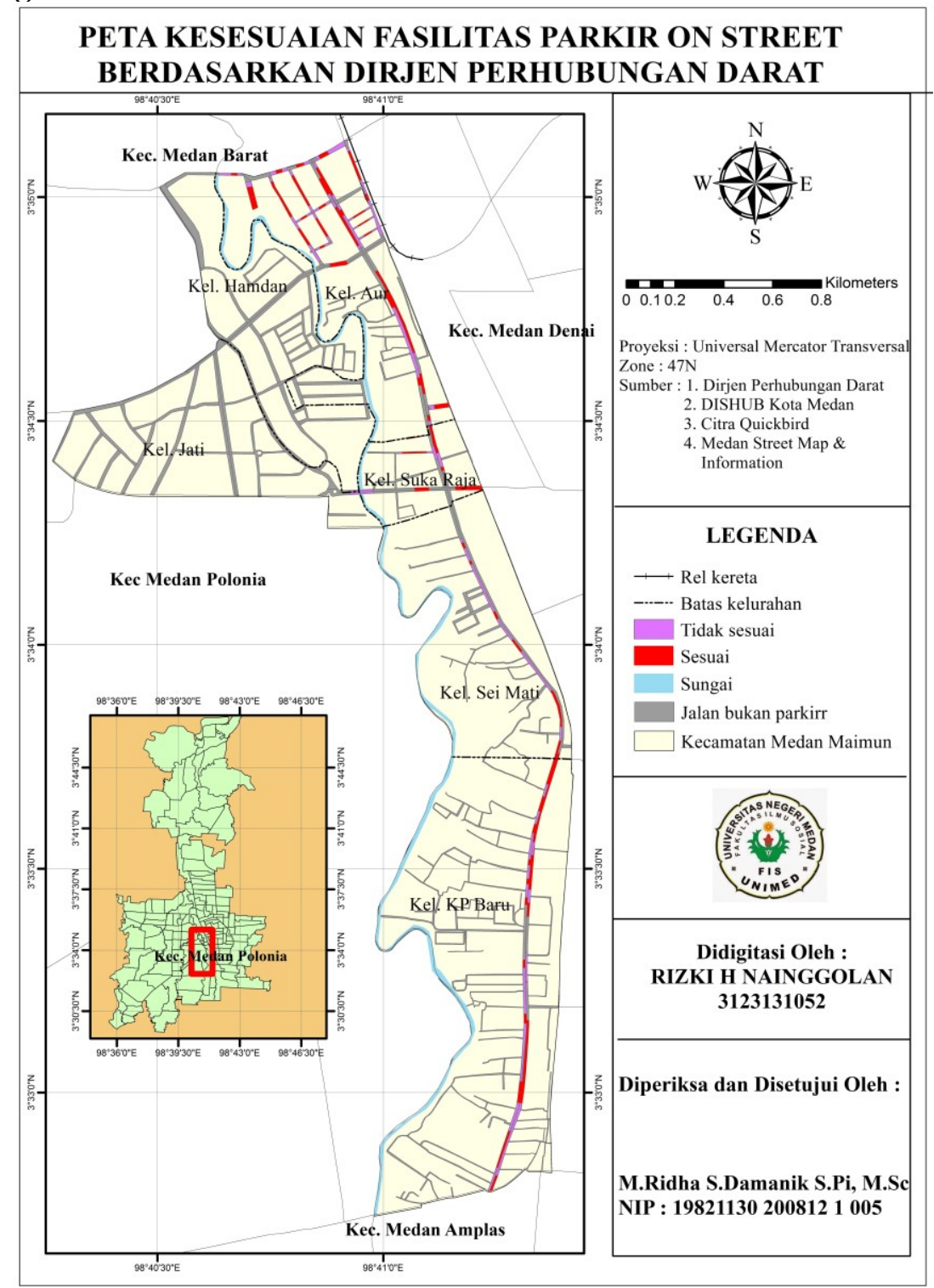

Gambar 2. Peta Kesesuaian Parkir Kecamatan Medan Maimum Kota Medan

Berdasarkan hasil penghitungan tingkat akurasi citra (Tabel. 4) yaitu dengan cara melakukan perbandingan tingkat kesalahan perhitungan terhadap pengukuran dalam lapangan dan kemudian dinyatakan dalam \%, maka didapatkan tingkat akurasi interpretasi citra quickbird dalam menganalisis panjang jalan adalah $98.03 \%$. Hal ini menunjukkan bahawa interpretasi citra quickbird 
dinyatakan sangat baik digunakan sebagai bahan analisis kesesuain jaringan jalan

dengan tingkat akurasi $>90 \%$.

Tabel 4. Perhitungan Tingkat Akurasi Citra Quickbird

\begin{tabular}{ccccc}
\hline \multirow{2}{*}{ No } & \multirow{2}{*}{ Sampel } & \multicolumn{2}{c}{ Pengukuran } & \multirow{2}{*}{ Kesalahan } \\
\cline { 3 - 4 } & & Citra & Lapangan & \\
\hline 1 & Titik 1 & 20,4 & 19,8 & 0,6 \\
2 & Titik 2 & 14,1 & 14 & 0,1 \\
3 & Titik 3 & 6 & 5,8 & 0,2 \\
4 & Titik 4 & 5,2 & 5,1 & 0,1 \\
5 & Titik 5 & 5,3 & 5,23 & 0,07 \\
6 & Titik 6 & 9,7 & 0,4 \\
7 & Titik 7 & 10,1 & 13,5 & 0,3 \\
8 & Titik 8 & 14,8 & 14 & 0,1 \\
9 & Titik 9 & 14,3 & 14 & 0,3 \\
10 & Titik 10 & 14,1 & 14 & 0,1 \\
\hline & Jumlah & 117,4 & 115,13 & 2,27 \\
\hline
\end{tabular}

Sumber : Hasil analisis interpretasi citra dan Pengukuran lapangan

\section{KESIMPULAN DAN SARAN}

Berdasarkan hasil analisis kesesuaian fasilitas parkir on-street yang telah dilakukan maka disimpulkan, bahwa sebaran fasilitas parker on-street di Kecamatan Medan Maimun memusat di Kelurahan Aur yang terletak di sebelah utara wilayah Kecamatan Medan Maimun. Hal ini disebabkan karena keluruahan tersebut merupakan kawasan yang relatif sibuk.

Prosentase fasilitas parkir on-street yang sesuai dengan aturan Direktorat Jenderal Perhubungan Darat. adalah sebesar $54.49 \%$ sedangkan 45,51\% dinyatakan tidak sesuai. Kriteria larangan parkir $25 \mathrm{~m}$ sebelum dan sesudah persimpangan adalah area yang sering dilanggar dalam penetapan fasilitas parkir on-street di Kecamatan Medan Maimun. Terdapat $46.74 \%$ dari total jaringan jalan Kecamatan Medan Maimun dapat direkomendasikan sebagai fasilitas parkir on-street sesuai dengan peraturan Dirjen Perhubungan Darat.

Pemanfaatan citra quickbird dan sistem informasi geografi sebagai bahan dan teknik dalam analisis kesesuaian fasilitas parkir on-street di Kecamatan Medan Maimun sangat baik digunakan dengan tingkat akurasi lebih dari $90 \%$.
Hal yang dapat disarankan berdasarkan hasil penelitian ini adalah agar Dinas Perhubungan Kota Medan melakukan evaluasi kembali terhadap penetapan fasilitas parkir on-street berdasarkan Keputusan Menteri Perhubungan No:66 tahun 1993 Tentang Fasilitas Parkir untuk Umum dan Keputusan Dirjen Perhubungan Darat Nomor: 272/HK.105/DRJD/1996 on-street sehingga masalah kemacetan lalu lintas akibat parkir on-street dapat diatasi. Selain itu, peletakan Marka jalan tentang fasilitas parkir diperjelas dan ditegaskan dengan rambu jalan larangan parkir.

Bagi penelitian berikutnya agar penelitian ini dapat dijadikan referensi untuk menanalisis keseuaian parkir onstreet pada lokasi yang lain yang memiliki masalah kemacetan lalu lintas yang diakibatkan oleh fasiltas parkir on-street.

\section{DAFTAR PUSTAKA}

Alamsyah, Alik Ansyori. 2008 "Rekayasa Lalu Lintas". UMM Press. Malang

Andriana. 2012. " Sistem Informasi Geografif Titik Lokasi Parkir Pada Dinas Perhubungan Kota Medan". Skripsi. Medan 
Anon, 2001, Sistem Informasi Geografis (GIS)

http://Blog_wilsarbali.blogspot.com2 010/02/sistem -informasi-geografigis-lanjutan.html, diakses 30 mei 2016.

Barus, B dan U. S. Wiradisastra. 2000. Sistem Informasi Geografi Sarana Manajemen Sumberdaya. Laboratorium Penginderaan Jauh dan Kartografi. Jurusan Tanah. Fakultas Pertanian. IPB. Bogor.

Direktorat Bina Sistem Lalu Lintas dan Angkutan Kota Direktorat Jenderal Perhubungan Darat. 1998. "Pedoman Perencanaan dan Pengoperasian Fasilitas Parkir". Dlt BSLLAK. Jakarta.

Dulbahri, 1985. Interpretasi Citra Untuk survey Vegetasi. Puspics Bakorsurtanal - UGM, Yogyakarta.

Hobbs, F.D. 1995. "Peerencanaan dan Teknik Lalu Lintas. Gajah Mada University Press. Yogyakarta

Indarto. 2013. “Teori dan Praktek Penginderaan Jauh". Penerbit Andi. Yogyakarta

Indrawati, 2002, sistem informasi geografi (SIG)/Geographic Informastion System

(GIS),

http://mbojo.wordpres.com/2007/04 /08sistem-informasi-geografi-sig/, diakses 30 mei 2016

Ismiyati. 2004. "Kajian Penentuan Kebutuhan Standart Kebutuhan Parkir Hotel Berbintang di Kota Semarang". Skripsi. Semarang.

Kusuma, Tirta. 2012. "Pengawasan Penyelenggaraan Retribusi Parkir Oleh Dinas Perhubungan, Komunikasi dan Informatika Kota Serang. Skripsi. Serang

Lukman, 1993, Sistem Informasi Geografis (GIS)

http://Blog_wilsarbali.blogspot.com2 010/02/sistem -informasi-geografigis-lanjutan.html, diakses 30 mei 2016
Nugaraha, Martinus Ari Agung. 2007. “Analisis Kapasitas Ruang Parkir Off Street Sepeda Motor Ada Swalayan Setia Budi Semarang. Skripsi. Semarang

Nursanti, 1995, sistem informasi geografis(GIS) - Lanjutan http://Blog_wilsarbali.blogspot.com2 010/02/sistem -informasi-geografigis-lanjutan.html, diakses 30 mei 2016

Oglasby, Clarkson H dan Hicks R. Gary. 1993. “Teknik Jalan Raya”. Erlangga. Jakarta

Wibowo, Kurnia Tri. 2010. “Hukum Lalu Lintas dan Jalan". Ebook.

Prahasta, Eddy. 2014. "Sistem Informasi Geografis". Informatika. Bandung

Prahasta. 2008. “Konsep - Konsep Sistem Informasi Geografis. Teknik Informtika Universitas Negeri Malang. Malang

Safitri, Benita. 2012. “ Pengelolaan Parkir ON Street Oleh Pengelola Perparkiran DKI Jakarta. Jakarta.

Tatura, Lidya Surijany. 2011. “Analisis Penataan Ruang Pakir Pasar Central Kota Gorontalo". Skripsi. Gorontalo

Ulfa, Annisa Nur. 2013. “Kajian Kondisi Parkir Berdasarkan Kebutuhan dan Karakteristik Kawasan Singosaren Kota Surakarta. Skripsi. Surakarta

Wikantika, Ketut dan Fajri, Lisa. 2012. "Bunga Rampai Penginderaan Jauh Indonesia". Pusat Penginderaan Jauh Institut Teknologi Bandung. Bandung. 